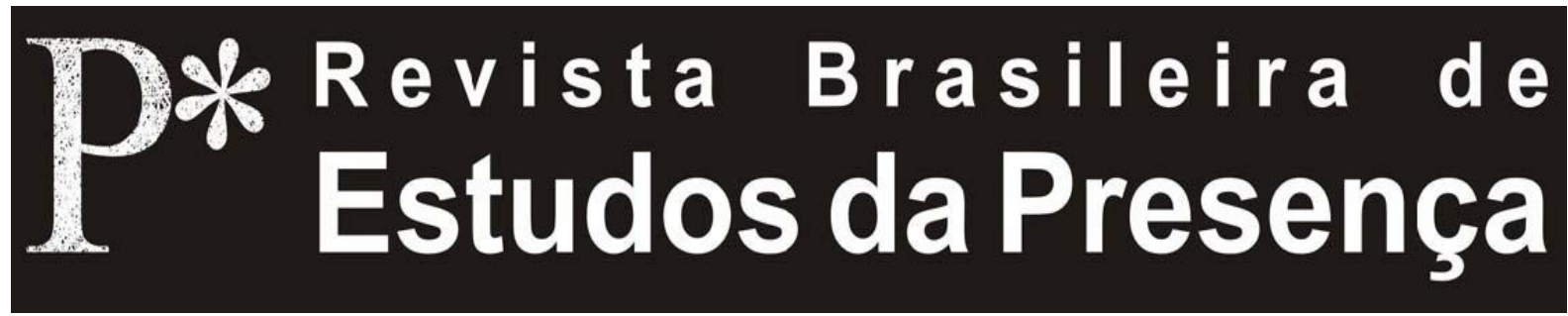

DOI - http://dx.doi.org/10.1590/2237-266033250

ISSN 2237-2660

\title{
Sobre The Living Room
}

Thomas Richards

Workcenter of Jerzy Grotowski and Thomas Richards - Pontedera, Itália

RESUMO - Sobre The Living Room $^{1}$ - Este texto trata da obra, dirigida pelo autor, intitulada The Living Room e reflete sobre seus sentidos e funçóes. O artigo coteja os problemas que a performance levanta em relação à vida social contemporânea, aduzindo ao isolamento da vida hoje e às possibilidades da performance para rompê-lo. Problematiza-se a crise vivida pelo autor e a consequente criação da obra como dispositivo performático móvel em relação ao espaço de apresentação. Por fim, o trabalho questiona as formas de interação e o tipo de participação possível na performance.

Palavras-chave: Jerzy Grotowski. Workcenter of Jerzy Grotowski and Thomas Richards. The Living Room. Teatro. Público.

ABSTRACT - On The Living Room - This text discusses the work The Living Room, directed by the author, and reflects on its meanings and functions. The article confronts problems performance raises in relation to contemporary social life, bringing forward the isolation of life today and the possibilities performance offers to fight it. We problematise the crisis experienced by the author and the consequent creation of the work as a mobile performative device in relation to the staging space. Finally, the work questions the forms of interaction and type of participation possible in performance.

Keywords: Jerzy Grotowski. Workcenter of Jerzy Grotowski and Thomas Richards. The Living Room. Theatre. Public.

RÉSUMÉ - Sur The Living Room - Ce texte propose une réflexion à la fois sur le sens et sur les fonctions du spectacle The Living Room, mis en scène par l'auteur. Larticle s'attache également aux problèmes soulevés par la performance en ce qui concerne la vie sociale contemporaine, mettant en évidence l'isolement caractéristique de la vie actuelle et les possibilités qu'offre la performance pour le rompre. La crise vécue par l'auteur et la création de l'œuvre qui s'en est suivie sont envisagées ici en tant que dispositif performatique mobile par rapport à l'espace de sa présentation. Enfin, le travail questionne les formes d'interaction et le type de participation possibles dans la performance.

Mots-clés: Jerzy Grotowski. Workcenter of Jerzy Grotowski and Thomas Richards. The Living Room. Théâtre. Public. 
Estamos mergulhados em um mundo cada vez maior de redes de informação, e, ironicamente, quando o mundo está mais ao nosso alcance, estamos nos habituando com o mundo das interaçóes mediadas confortavelmente separado. Nós nos relacionamos uns com os outros cada vez mais por intermédio de telas. Em geral, nossas casas estão equipadas com um número suficiente delas para nos manter bastante ocupados, e nossas salas de estar são centrais de mídia. Recentemente, um amigo me contou que envia e-mails para sua esposa mesmo quando eles estão no mesmo cômodo.

$\mathrm{O}$ que pode acontecer em uma sala de estar? Sentimos que, nesse cômodo, algo pode sem dúvida acontecer, o seu nome [em inglês, living room] já traz o projeto de um possível evento, um lugar onde a vida pode se desemaranhar e nos revelar seu potencial escondido. Mas, de alguma forma, essa açáo essencial que pode acontecer nesse cômodo, ou, aliás, em qualquer outro cômodo, parece estar ficando cada vez mais distante, na medida em que nossa atençáo desloca-se do reunir-se e do interagir para o fascinante mundo virtual.

Enquanto o mundo virtual que vem se desenvolvendo é uma manifestação do progresso extremo e rápido da conectividade, sua forma está ao mesmo tempo enraizada em nossos maiores e mais simples medos e mecanismos. Ele nos fornece uma extrema forma de proteçáo e, ao mesmo tempo, tenta satisfazer nossa necessidade de contato e exposiçấo. Quando estou online, estou conectado com todo mundo e com ninguém. Ironicamente, quando envolvido com a web, estou em contato acelerado com tantos e, ao mesmo tempo, em um isolamento poderoso, um isolamento que, talvez, sempre tenha estado presente em nossas vidas, e pelo qual náo podemos simplesmente responsabilizar a sua manifestação contemporânea chamada Internet, mas que, no entanto, cresce exponencialmente e que nos oferece um meio de evitar nosso medo dos outros.

The Living Room ${ }^{2}$ pergunta: podem as artes performativas - uma arte de conectividade inter-humana e interpenetração - nos ajudar a sair do isolamento? Nosso ofício, por sua natureza, já propóe essa possibilidade. Ele pode nos levar a um território no qual o isolamento diário, pessoal e interpessoal pode ser ativamente confrontado e transformado. Que tipo de interconexão é possível face a face? Que tipo de ressonância e experiência interior podemos receber quando em proximidade com outro ser humano? $\mathrm{O}$ que faz com que um cômodo tenha vida? O que faz de algo cotidiano, extraordinário? 
Muitas vezes, é a maneira com a qual tratamos os detalhes da vida diária que nos dá a oportunidade de realmente vivê-la. A preparaçáo da comida, quando vista como uma tarefa, um trabalho diário, pode parecer uma atividade monótona e repetitiva, servindo apenas ao absurdo de se viver por tempo suficiente para realizar essa atividade de novo e novamente. Por outro lado, como o ato de cozinhar pode ser uma ação que alimenta, que não apenas enche nossos estômagos, mas que começa a dar substância, no sentido de significado, conteúdo, ao processo da vida? A distinção é crucial, pois nela vemos a diferença entre viver a vida no piloto automático e viver a vida como um ser humano, considerando as complexas necessidades potenciais que existem em uma pessoa em determinado momento. Ao renovar o esforço na preparação de uma refeição e na oportunidade que ela oferece para encontrarmos outras pessoas, há a possibilidade de que uma substância passe de um indivíduo a outro, algo que não é apenas material, mas um tipo de conteúdo humano. Prepara-se o palco para um encontro.

O Workcenter está completando vinte e cinco anos ${ }^{3}$. Para que uma organização criativa possa manter um processo vivo por tanto tempo, uma reavaliação contínua se faz necessária. É como conduzir um barco - não se pode cruzar o Oceano Atlântico posicionando as velas de uma vez por todas. Na busca pela direçáo criativa que nosso trabalho necessita, descobrimos que essas direçóes criativas aparecem frequentemente em fases, em ondas de tempo, que normalmente duram alguns anos. A atual onda criativa no trabalho começou para mim em 2008, quando era o momento natural de encontrar um novo time de jovens dentro do trabalho e iniciar uma nova aventura com eles. Enfrentando esse momento, eu precisava reexaminar minha relaçáo com o trabalho, com seus processos, o que era verdadeiramente o equivalente a examinar minha própria vida. Percebi que me sentia feliz com o que havia sido realizado ao longo dos anos de atividade do Workcenter. No entanto, senti que algo no modo como eu tinha formado a minha vida, ou como minha vida gradualmente me formara, havia se tornado fácil demais para mim. Percebi uma peculiaridade na minha vida que comecei a chamar de os diferentes chapéus de Thomas. Havia o chapéu do atuante dentro do trabalho, que tinha nascido do meu trabalho com Grotowski como um atuante na Downstairs Action e depois em Action, etc.; havia o chapéu do criador que se desenvolveu através das obras que eu fui o 
responsável por criar dentro do Workcenter; consequentemente, havia o chapéu do Diretor Artístico, que é responsável por fazer com que o trabalho sobreviva e desenvolva-se a longo prazo; havia o chapéu do representante do trabalho para o mundo, o conferencista, aquele que dá um passo para fora do trabalho, com um pé dentro e outro fora, e analisa seus processos para aqueles que estáo do lado de fora; e havia, também, novos chapéus que a vida tinha oferecido, tal como aquele de marido, pai e chefe de família. Com certeza, quase todos podem sentir esse tipo de compartimentalizaçáo de diferentes partes de si, e, provavelmente, a um certo ponto, é normal fazer com que certas partes de si mesmo fiquem disponíveis para realizar diferentes tarefas. Há lógica nisso, um modo de preparar um rosto para suportar e agir com eficiência no mundo, uma forma de proteçáo para que se possa cumprir vários papéis com o mínimo de atrito, cada um de acordo com o que ele exige. Mas, ao mesmo tempo, há um aspecto potencialmente absurdo nessa tendência, pois nesse processo de compartimentalização, partes de uma pessoa podem permanecer separadas das outras, e até mesmo situaçôes podem começar a ditar o eu que irá se apresentar em determinado momento. No entanto, como eu aprendi a usar esses diferentes chapéus, me sentia muito orgulhoso, cada um desses chapéus exigia muito de mim e eram verdadeiros desafios. Ainda assim, com o tempo, eu comecei a sentir-me cada vez mais confortável usando-os. Comecei a temer esse conforto, pois, às vezes, no conforto pode haver as sementes de uma possível esterilidade.

Comecei a me sentir ansioso. Em 2008, entrei em uma espécie de crise criativa na qual desenvolvi uma alergia ao nosso espaço de trabalho. Eu não sabia a razão disso, mas não queria entrar na sala de trabalho, o que a meu ver era um sintoma da necessidade de me libertar dessa compartimentalizaçáo. Perguntas me vinham à mente: por que o trabalho deveria acontecer necessariamente no espaço de trabalho? Por que o diálogo com aqueles de fora do trabalho deveria acontecer fora do trabalho? Com todos esses diferentes chapéus, a sensaçáo era a de que eu estava me dividindo em uma série de caixas bem definidas. Eu sabia que alguma coisa deveria mudar no processo com esses jovens para que algo vivo aparecesse, e também para que eles fossem capazes de capturar algo da essência do nosso trabalho.

Eu não sabia o que fazer. Continuei indo ao espaço de trabalho e, por um lado, o trabalho com o novo time estava se desenvolvendo 
bastante bem. Mas, minha ansiedade aumentava. Eu precisava me libertar de alguma coisa. Então, no outono de 2009, com dois membros do time, parti em uma viagem através da Polônia, dirigindo por todo o país, por três semanas, de cidade em cidade e encontrando diferentes artistas e grupos de teatro, trabalhando e apresentando nosso trabalho em desenvolvimento onde quer que estivéssemos: porôes, salas de ensaio, becos, salas de aula, entradas de teatros e casas. Foi uma jornada na qual a intenção era gerar encontros. Às vezes, quando você está em um momento de requestionar sua vida e sua própria direção, é importante náo olhar apenas para você mesmo. Se você faz o oposto, se você olha para fora, para os outros, de alguma forma há a chance de encontrar a resposta para suas próprias perguntas. Nós partimos nessa jornada dizendo para nós mesmos que o mais importante seriam aqueles que nós encontraríamos, e não o que iríamos apresentar. A ênfase estava em conhecer o trabalho e a situação deles. A jornada nos levou a olhar para a realidade das outras pessoas. Nós os encontramos nas suas próprias e difíceis condiçóes e fomos confrontados com as realidades nas quais esses artistas lutam, sobrevivem e seguem seus impulsos para a criação. Nessa jornada, indo de uma cidade para outra a cada dois dias, entrando em contato com tantas realidades, tantos lares diferentes, comecei a sentir como uma liberdade em relação à compartimentalização. Nosso trabalho podia existir em qualquer lugar e em qualquer momento. Os processos que estáo envolvidos na Arte como Veículo, na verdade, vêm de uma necessidade que se pode perceber dentro de si mesmo em momentos específicos ao longo do dia. Uma voz interior que nos chama para subir, para transcender o peso acumulado pode aparecer para desfazer os nós que surgiram. $\mathrm{O}$ trabalho pode ouvir e responder a essa necessidade, fora de caixas predeterminadas.

Durante a nossa viagem, a obra na qual estávamos trabalhando começou a se cristalizar e quando encontramos os outros membros da equipe em Wroclaw, Polônia, onde estávamos em uma residência por alguns meses, nós imediatamente agarramos essa possibilidade. Náo trabalhamos no espaço pré-determinado. Trabalhamos em um dos pequenos apartamentos onde alguns dos membros do time estavam hospedados. Lá, continuamos a desenvolver a obra. Nós também começamos a convidar novos amigos que fizemos durante a viagem pela Polônia para juntarem-se a nós e estarem presentes no 
apartamento enquanto trabalhávamos. As primeiras sessóes de The Living Room aconteceram lá.

Quando retornamos à Itália, tínhamos o desejo de não voltar aos nossos hábitos. Então, começamos a trabalhar na minha própria casa, deixando que o ato da passagem do cotidiano à experiência performática altamente estruturada, que nos ajudava a tocar em aspectos extraordinários da experiência interior e do contato interhumano, acontecesse dentro de uma casa. Nós apenas retornamos ao nosso espaço de trabalho em Vallicelle muitos meses depois, depois que The Living Room já havia desenvolvido sua base vital que nasceu no trabalho em casa. E agora, quando vou para o espaço de trabalho para fazer The Living Room, sinto-me, na verdade, como um convidado, sinto-me como se estivesse de passagem, que é como eu me senti anos atrás quando cheguei ao Workcenter, e, também, como provavelmente sempre nos sentimos quando, de fato, prestamos verdadeira atenção ao que está à nossa volta. Nada é nosso, nem mesmo meus próprios compartimentos são meus. Uma qualidade da ação pode passar para a outra, quase imperceptivelmente. Eu náo preciso colocar muros entre elas.

The Living Room não é um retorno ao parateatro. Aquele que assiste ao trabalho náo se torna um participante ativo; ele ou ela é um convidado. Depois que o trabalho da performance termina, no entanto, há uma certa suspensão. Se o trabalho funciona bem, posso deixar que meus chapéus se dissolvam. Podemos comer, conversar, um momento transparece no qual os fluxos da vida que foram evocados pelo trabalho podem sutilmente viver e circular entre as pessoas. Em um desses momentos, um homem que ficou abalado com The Living Room disse-me, "sabe, na maioria das vezes que vou ao teatro eu devo admitir que eu realmente odeio; em geral, há algo morto no teatro, pra mim”. Mas seria o teatro aquilo que está morto? Temos ouvido essa frase por anos e, se há algo verdadeiro nela, devo entendê-lo de modo pessoal.

Para mim, o que está morto no teatro de hoje é o anonimato na situação performática. Quando vou ao teatro, normalmente, sento-me com muitas pessoas, as luzes se apagam, e eu mergulho em um mar de anonimato. Um ator aparece no palco, alguém que não conheço e que nunca conhecerei, e eu assisto ao desenrolar da ação. Os atores saem, eu bato palmas ou não e vou embora. Talvez eu tenha sido tocado, talvez eu entenda. Mas, mesmo no melhor dos casos, os muros de proteção permanecem intactos. Eu estou seguro 
em meu anonimato e o ator também está seguro dentro do dele ou dela. Estranhamente, mesmo atores que fazem grandes turnês vivem em um tipo de anonimato. Os festivais quase sempre têm orçamentos limitados e querem que os artistas cheguem e saiam o mais rapidamente possível. Geralmente, os artistas montam tudo em um dia, realizam sua performance e saem no dia seguinte. É possível para um artista viajar pelo mundo, ser visto por milhóes de pessoas e encontrar com quase ninguém além das paredes de quartos de hotel. Bem, essa situação performativa pode produzir resultados de qualidade, mas, do meu ponto de vista, falta algo nesse tipo de situaçáo. O teatro nunca poderá competir com o nível de anonimato oferecido por filmes e pela televisão e, em especial, pela Internet. Nessas formas de interação, a arte do anonimato é realizada com perfeição. O que pode ser mais anônimo do que estar em casa na sua sala de estar, assistindo à televisão ou navegando na Internet, conectado a todos ao mesmo tempo em que se é anônimo, apenas um nome de usuário, um perfil? Esse tipo de anonimato náo é para onde eu quero que a carruagem da minha vida se dirija, náo é a estrada na qual eu quero caminhar. Essa parece ser uma grande e poderosa onda na nossa sociedade, mas, quando há uma grande onda, sempre há a possibilidade de um pequeno riacho movendo-se na direção oposta. Em todas as épocas, pequenas contracorrentes existem; elas oferecem equilíbrio, uma oposição sem a qual tudo se torna homogêneo. O Workcenter cria uma contracorrente que tira os seres humanos do anonimato, os póe em contato, usando o ofício das artes performativas como uma maneira de restabelecer conexóes inter-humanas, indo até mesmo contra os nossos próprios desejos de isolamento e proteção.

Nós realizamos The Living Room em condiçóes muito variadas: não apenas em festivais ou convidados por teatros, mas também em casas, na estrada, como um evento surpresa, durante uma visita, em lugares onde as pessoas se encontram e onde pode haver interação recíproca, um momento de reuniáo. Esse movimento expansivo envolve a todos nós em um diálogo que traz respostas que podem surgir caso olhemos para o outro com consideração. Talvez o importante náo seja apenas compartilhar o trabalho de performance, mas o porquê e quem são aqueles que encontramos, uma questáo por trás da qual há uma intenção completamente diferente, pois ela está direcionada para fora de nós mesmos e está fora da situação de nossos próprios esforços. 


\section{Notas}

${ }^{1}$ Agradeço a Philip Salata por seus esforços na redaçáo deste texto.

${ }^{2}$ N.R.: The Living Room é um espetáculo do Workcenter of Jerzy Grotowski and Thomas Richards.

${ }^{3}$ Trata-se de um texto escrito em 2011.

Thomas Richards é ator e diretor. É o diretor artístico do Workcenter of Jerzy Grotowski and Thomas Richards. Dirige, desde 2007, dentro do Workcenter, o Focused Research Team in Art as Vehicle. Trabalhou diretamente com Grotowski de 1985 até sua morte. Em 1996, Grotowski colocou o nome de Richards ao lado do seu no Workcenter, marcando, com esse ato e também com uma série de declaraçóes, o lugar de Richards como o herdeiro e continuador de suas investigaçóes. Richards é autor, entre outros livros, de Trabalhar com Grotowski sobre as Ações Físicas, lançado pela Editora Perspectiva.

E-mail: info@theworkcenter.org

Traduzido do original em inglês por Martin Heuser. Revisão técnica de Tatiana Motta Lima e Carla Pollastrelli.

Recebido em 29 de setembro de 2012 Aprovado em 01 de novembro de 2012 